\title{
Severely depressed interleukin-17 production by human neonatal mononuclear cells
}

\author{
Justin E. Caron' ${ }^{1}$ Timothy R. La Pine ${ }^{2,3}$, Nancy H. Augustine' ${ }^{1}$, Thomas B. Martins ${ }^{4}$, Attila Kumánovics' and Harry R. Hill ${ }^{1,2,4}$
}

BACKGROUND: The role of T-helper 17 cells (Th17) in neonatal host defense remains to be fully elucidated. Interleukin (IL)17 plays an important role in the immune response to bacterial and fungal pathogens by promoting inflammation.

METHODS: We examined neonatal production of $\mathrm{IL}-17$ in mixed mononuclear cells (MMCs) isolated from umbilical cord blood for comparison with adult peripheral blood mononuclear cell controls.

RESULTS: IL-17 production was profoundly diminished in MMCs isolated from cord blood when compared with MMCs from adult blood. This was associated with a marked reduction in the population of CCR6 $6^{+} \mathrm{IL}-17^{+}$T-cells in the neonatal cord blood. We also found diminished intracellular formation of IL-17, and diminished IL-17 responses to both group B streptococci (GBS) and Escherichia coli. Neonatal mononuclear cells were found to adequately phosphorylate signal transducer and activator of transcription 3, pY705, and pS727. We and others have reported markedly reduced interferon- $\gamma$ production by neonate mononuclear cells exposed to GBS. Here, we correct that profound abnormality with added IL-17.

CONCLUSION: Our results suggest that profound deficiency of IL-17 production associated with a marked decrease in Th17 cells likely contributes significantly to the increased susceptibility of human neonates to invasive bacterial and fungal infections.

$\mathbf{H}$ uman neonates are uniquely susceptible to severe and overwhelming bacterial and fungal infections $(1,2)$. Many abnormalities of neonatal host defense have been reported to date. Consistent among these are observations of decreased cytokine production and defective inflammatory responses. T-helper 17 (Th17) cells and interleukin (IL)-17 play an important role in phagocyte recruitment, activation, and migration to sites of inflammation $(3,4)$. Th17 cells have recently been isolated and characterized in humans, and represent a distinct subset of helper $\mathrm{T}$ cells in addition to those of the Th1/Th2 paradigm (4-7). Th17 cells are a subset of memory $\mathrm{CD} 4^{+} \mathrm{T}$ cells that produce IL-17 and express the IL-23 receptor (IL-23R) (4-7). The role of Th17 cells in neonatal host defense remains to be fully elucidated.
Studies in knockout mice have shown that IL-17 is required for the host response to Gram-positive, Gram-negative, and fungal infections (8-10). For example, IL-17 mediates immunity to Gram-negative bacterial infections, and mice lacking the IL-17 receptor show decreased neutrophil recruitment and higher mortality in experimental Klebsiella pneumoniae pneumonia (8).

We have reported defects in neutrophil migration and signal transduction in human neonates (11-14). Furthermore, we have suggested that deficiencies of cytokine production, including IFN- $\gamma$, likely play a role in the increased susceptibility of human neonates to bacterial pathogens (12-14). To our knowledge, Th17 cell populations in human neonates have not yet been fully described. Here, we employ phytohemagglutinin (PHA), heat-inactivated group B streptococci (GBS), and Escherichia coli as stimulants, and measure IL-17 responses in mixed mononuclear cells (MMCs) isolated from umbilical cord blood, using an in-house developed multiplex cytokine panel (15), and compare these responses to those of mononuclear cells from healthy adult controls. Additionally, we employ a flow cytometry assay adapted from Eyerich $e t$ al. (16), to examine cord blood for $\mathrm{CD}^{+} \mathrm{CD}^{-} \mathrm{T}$ cells that express CCR6, a surface Th17 cell marker, as well as intracellular IL-17. To examine intracellular STAT3 phosphorylation, we stained resting cells that had been stimulated with IL- 6 and phorbol 12-myristate 13-acetate (PMA) with Alexa Fluor 647 mouse anti-STAT3 pY705 and pS727. Lastly, we show that added IL-17 dramatically improves neonatal mononuclear cell production of the critical Th1 cytokine interferon- $\gamma$.

\section{RESULTS}

\section{IL-17 Production Is Profoundly Diminished in Human Neonates Compared to Adults}

In response to stimulation with the potent mitogen PHA, mean IL-17 concentrations measured in tissue culture supernatant isolated from cord blood samples $(0.2 \mathrm{pg} / \mathrm{ml} \pm 0.1 \mathrm{SEM} ; n=$ 18) were found to be severely diminished when compared with mean IL-17 concentrations in tissue culture supernatant from adult blood (455.6 pg/ml \pm 120 SEM; $n=16),(P=0.0023)$.

Next, we determined mean IL-17 responses to the major neonatal pathogens GBS and E. coli. IL-17 production in

\footnotetext{
'Department of Pathology, University of Utah, Salt Lake City, Utah; ${ }^{2}$ Department of Pediatrics, University of Utah, Salt Lake City, Utah; ${ }^{3}$ St. Mark's Hospital, Salt Lake City, Utah; ${ }^{4}$ Associated Regional and University Pathologists (ARUP) Institute for Clinical and Experimental Pathology, Salt Lake City, Utah. Correspondence: Harry R. Hill (Harry.Hill@path.utah.edu) 
response to GBS was profoundly lower in MMCs isolated from cord blood (mean $=0.2 \mathrm{pg} / \mathrm{ml} \pm 0.09$ SEM; $n=10)$ compared to MMCs from adult controls (mean $=10.9 \mathrm{pg} / \mathrm{ml} \pm 2.8 \mathrm{SEM}$; $P=0.0041 ; n=12$ ) (Figure 1 ). The mean IL-17 response to $E$. coli was also significantly lower in neonates $($ mean $=0.0 \mathrm{pg} / \mathrm{ml}$ $\pm 0.0 \mathrm{SEM} ; n=18$ ) compared to adults (mean $=12.5 \mathrm{pg} / \mathrm{ml} \pm$ 5.7 SEM; $P=0.0013 ; n=12$ ) (Figure 1 ).

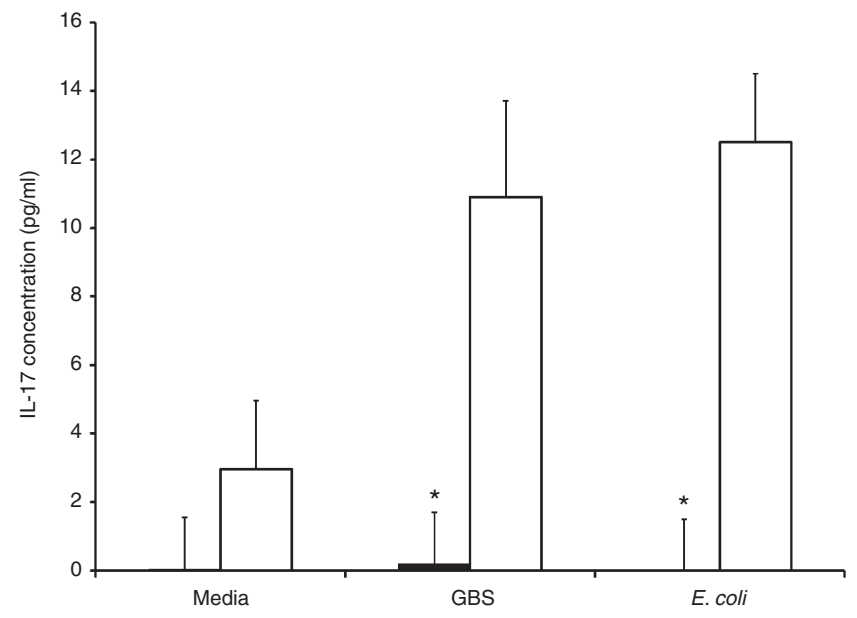

Figure 1. Interleukin (IL)-17 production in response to group B streptococci (GBS) and Escherichia coli. IL-17 production in response to both GBS and $E$. coli was significantly lower in neonates compared to adults. Mean IL-17 concentrations were $0.2 \mathrm{pg} / \mathrm{ml}$ and 0.0 in neonates for GBS and $E$. coli, respectively, compared to 10.9 and $12.5 \mathrm{pg} / \mathrm{ml}$ in adults. Data are from cord blood collected from healthy term deliveries $(n=10)$ and blood from healthy adult controls $(n=12)$. Error bars indicate SEM. * Significant differences in expression of IL-17 in cord blood compared to blood from adults, with $P<0.05$

\section{Human Neonates Exhibit a Decreased Total Number of IL-17 Producing CCR6 ${ }^{+} \mathrm{T}$ Cells}

Additional experiments were carried out on five adult controls and six neonatal cord blood samples, measuring mean intracellular production of IL-17 in CCR6 $6^{+}$Th $17^{+} \mathrm{T}$ cells by flow cytometry. For all experiments, CD69 upregulation was evaluated to ensure specimen viability. We also showed that CCR6 is not upregulated in response to PMA, indicating a stable Th17 cell population in our assay system. In our experience, CD4 downregulation can occur with PMA stimulation, so we chose a negative strategy gating $\mathrm{CCR}^{+} \mathrm{CD} 8$ negative $\mathrm{T}$ cells that stained positive for intracellular IL-17.

In our flow cytometry assay, PMA stimulation resulted in a roughly 10 -fold increase in the mean fluorescent intensity for IL-17-phycoerythrin conjugated signal in adult blood (Figure 2, panels a, b). PMA stimulation in neonates did not result in an increase in mean IL-17 fluorescence intensity (Figure 2, panels c, d). Cord blood IL-17 signal intensity was significantly diminished when compared to adult blood, with mean values of 993 relative units in neonates $(n=6)$, compared to 1,878 relative units in adults ( $n$ $=5),(P<0.05)$ (Figure 2, panel e). Staining for intracellular IL-17 and CCR6, we found that the CCR6 ${ }^{+}$IL-17 ${ }^{+}$T cell population was also significantly diminished in cord blood ( $n$ $=6)$ compared to adults $(n=5)$, following stimulation with PMA $(P=0.0001)$. Both PMA and IL-6 stimulated essentially the same increase in STAT3 pY705 and STAT3 pS727 phosphorylation in adult and cord blood leukocytes (Figure 3), indicating normal STAT 3 phosphorylation.

We next determined the effect of added human recombinant IL-17, $100 \mathrm{ng} / \mathrm{ml}$, to GBS induced neonatal mononuclear cell
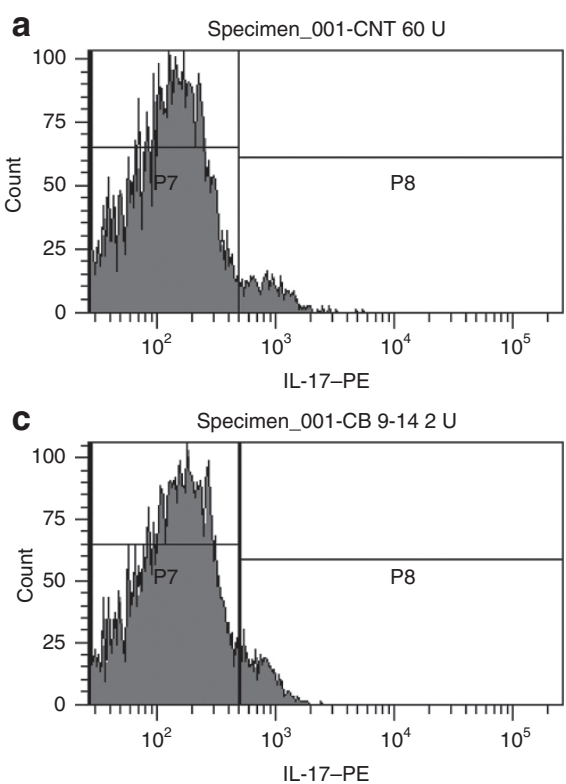

b

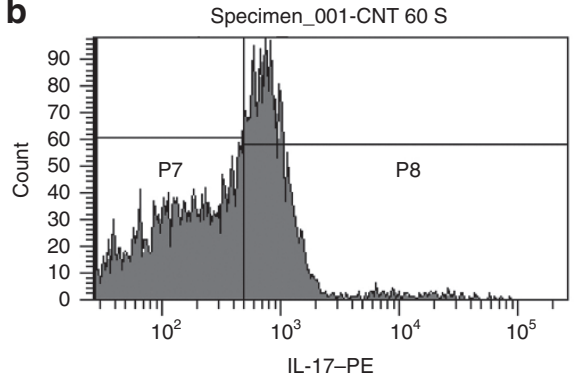

d

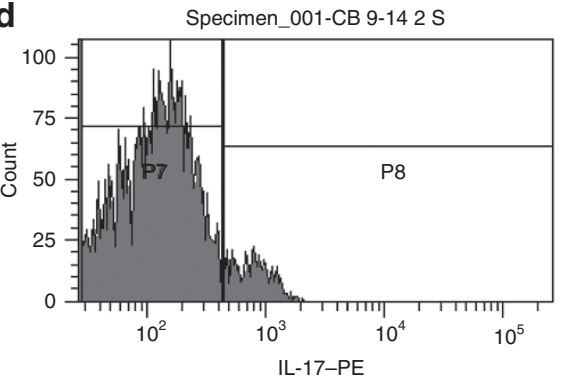

e

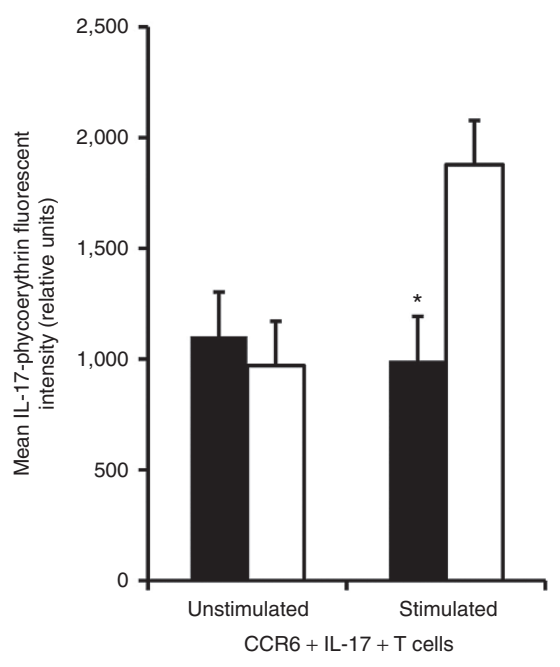

Figure 2. Mean phorbol 12-myristate 13-acetate (PMA)-stimulated interleukin (IL)-17-phycoerythrin (PE) fluorescent intensity in cord blood vs. adults. Following incubation with PMA, CCR6 ${ }^{+} \mathrm{IL}-17^{+} \mathrm{T}$ cells in adult controls $(n=5)$ demonstrated a roughly 10 -fold increase in mean fluorescent intensity, as seen here with a shift in peak signal intensity to the right, indicating an increase in IL-17 production (panels a,b). In contrast, no increase in signal intensity was seen in CCR6 $6^{+} \mathrm{L}-17^{+} \mathrm{T}$ cells from cord blood (panels $\left.\mathbf{c}, \mathbf{d} ; n=6\right)$; one representative experiment is shown each for cords and adults. Cord blood IL-17-phycoerythrin signal intensity (black bars; 993 relative units) was significantly diminished when compared to adult blood (white bars; 1,878 relative units). *Significant differences between PMA-stimulated adult and cord blood samples, with $P \leq 0.05$ ) (panel e). 


\section{Articles | Caron et al.}

a

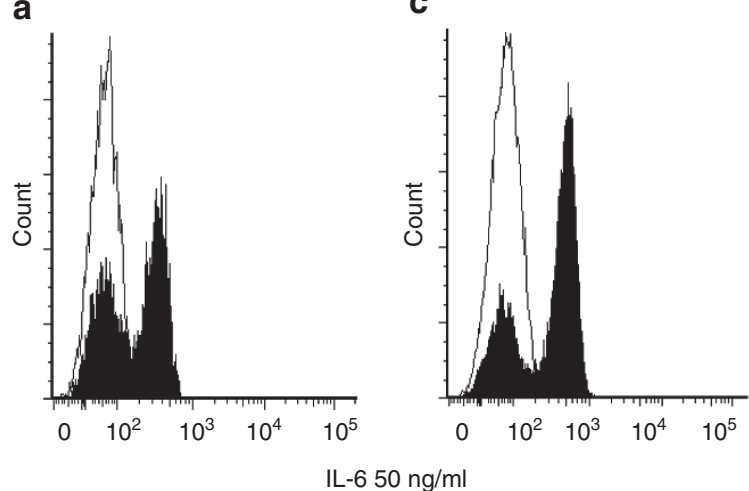

b

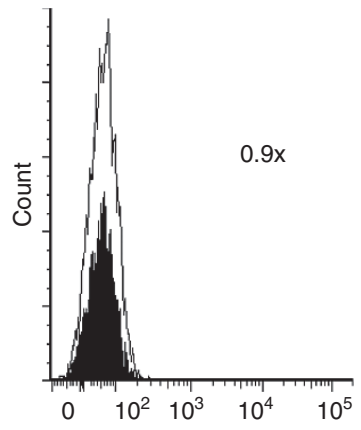

d

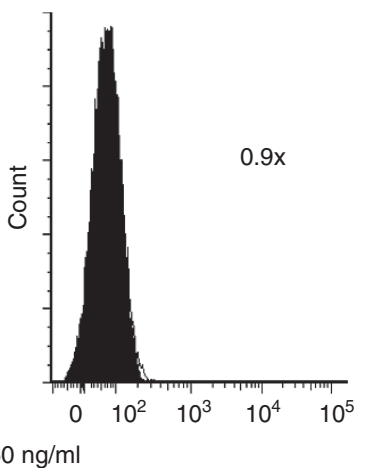

e

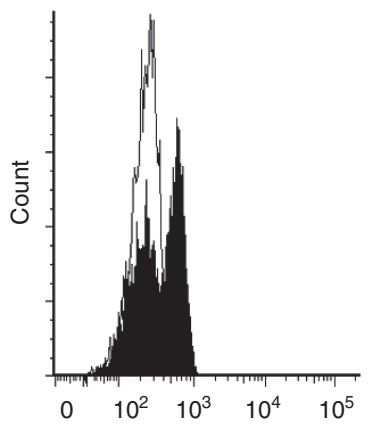

g
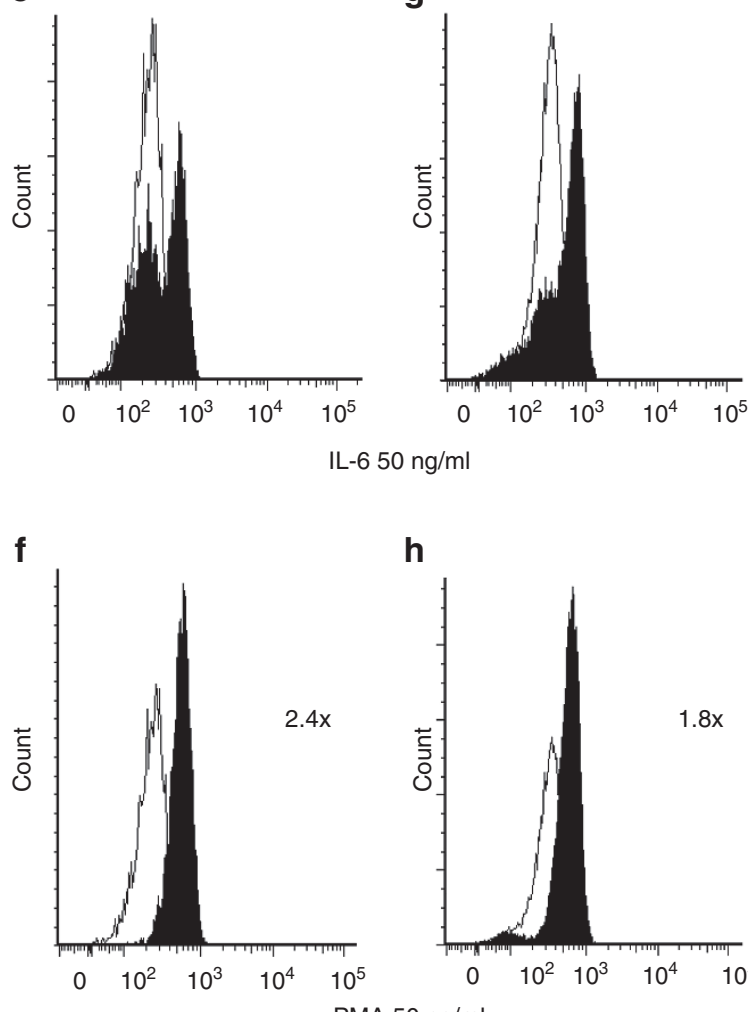

h

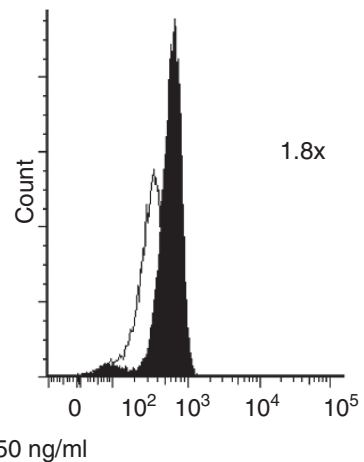

Figure 3. Mean interleukin (IL)-6 and phorbol 12-myristate 13-acetate (PMA)-stimulated phosphorylation of STAT3. Whole blood from normal adult controls $(\mathbf{a}, \mathbf{b})$ and umbilical cords (c,d) was incubated with rhlL-6 $(50 \mathrm{ng} / \mathrm{ml})$ or PMA $(50 \mathrm{ng} / \mathrm{ml})$ for $15 \mathrm{~min}$ at $37^{\circ} \mathrm{C}$. Cells were then treated with lyse/fix buffer, permeabilized, and stained with Alexa Fluor 647 mouse anti-STAT3 pY705 (panels a-d). Adult controls (e,f) and umbilical cords (g,h) were also stained with mouse anti-STAT3 pS727 (panels e-h) following similar treatment and incubation with rhlL-6 ( $50 \mathrm{ng} / \mathrm{ml}$ ) or PMA (50 ng/ml). White areas under the curve represent unstimulated and black areas under the curve stimulated. Values within histograms represent increase over baseline. Data shown are from a representative experiment. Similar results were observed in three experiments.

production of the TH1 cytokines IFN- $\gamma$, IL-2, and IL-12. IL-17 significantly enhanced the production of the major TH1 cytokine IFN- $\gamma$, which has major antibacterial and proinflammatory activities (Figure 4). The addition of IL-17 to adult mononuclear cells was also examined, both with and without GBS at various concentrations. For the addition of IL-17 alone, there was no significant difference between neonates (mean IFN- $\gamma$ of $6.9 \mathrm{pg} / \mathrm{ml}$ ) and adults (mean IFN- $\gamma$ of $4.5 \mathrm{pg} / \mathrm{ml} ; P=0.12$ ). Interestingly, the addition of IL-17 to GBS-primed adult MMCs had an anti-inflammatory-like effect for the production of IFN$\gamma$ that was not statistically significant (mean IFN- $\gamma$ of $16.1 \mathrm{pg} /$ $\mathrm{ml}$ with GBS alone compared to a mean IFN- $\gamma$ concentration of $5.0 \mathrm{pg} / \mathrm{ml}$ with GBS plus added IL-17 (10 ng/ml); $P=0.0642)$.

\section{Human Neonates Exhibit Profoundly Diminished Cytokine Production With PHA Stimulation}

Our in-house developed multiplex assay also demonstrated that in response to stimulation with PHA, neonates produce significantly lower concentrations of IFN- $\gamma(12.7 \mathrm{pg} / \mathrm{ml}$, adults: 98 pg/ml), TNF- $\alpha$ (534 pg/ml, adults: 2,111 pg/ml), IL-12 (2.8 pg/ml, adults: $83 \mathrm{pg} / \mathrm{ml})$, IL-2 (471 pg/ml, adults: $2,315 \mathrm{pg} / \mathrm{ml})$, IL-2r (376 pg/ml, adults: 2,315 pg/ml), and sCD40L (24 pg/ $\mathrm{ml}$, adults: $59 \mathrm{pg} / \mathrm{ml})$; $(P<0.05$ for all values $)$. Neonates also

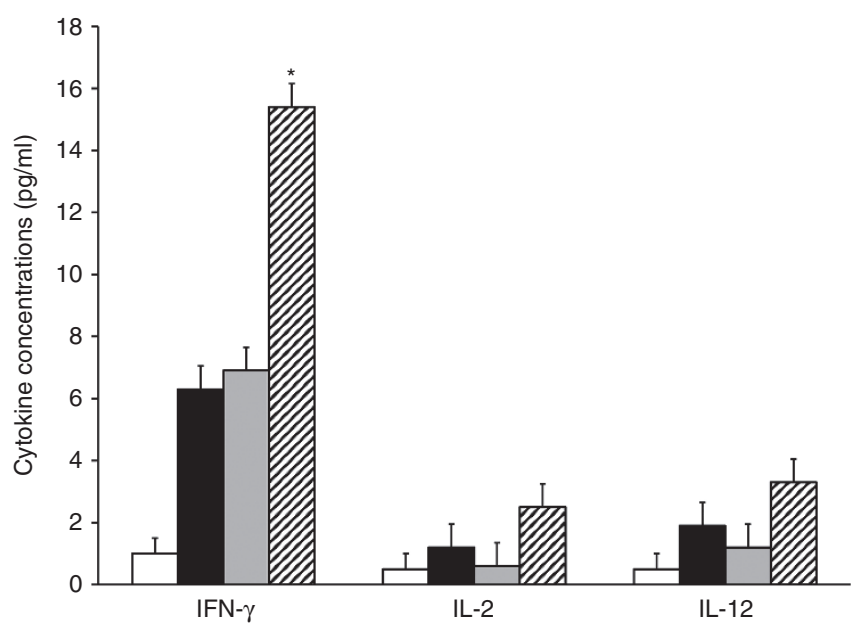

Figure 4. Effect of group B streptococci (GBS) and interleukin (IL)-17 $(100 \mathrm{mg} / \mathrm{ml})$ on neonatal mononuclear cell production of interferon (IFN)- $\gamma$, IL-2, and IL-12. Mononuclear cells from cord blood were incubated with GBS alone (black bars; $n=12$ ), IL-17 (gray bars; $n=4$ ), or GBS + IL-17 (hatched bars; $n=4$ ) and production of IFN- $\gamma$, IL-2, and IL-12 were determined. White bars represent unstimulated controls (media alone). The combination of GBS and IL-17 $(100 \mathrm{mg} / \mathrm{ml})$ significantly increased the production of IFN- $\gamma$ in cord blood, from $6.4 \mathrm{pg} / \mathrm{ml}$ (IL-17 alone), to $15.4 \mathrm{pg} /$ $\mathrm{ml}(\mathrm{GBS}+\mathrm{IL}-17) .{ }^{*}$ Significant difference with $P<0.05$. 
produced significantly lower concentrations of IL-4 (6.7 pg/ ml, adults: $854 \mathrm{pg} / \mathrm{ml})$, IL-5 (4.8 pg/ml, adults: $666 \mathrm{pg} / \mathrm{ml})$, and IL-10 $(160 \mathrm{pg} / \mathrm{ml}$, adults: $1,707 \mathrm{pg} / \mathrm{ml})$; $(P<0.05$ for all values). There was no statistically significant difference for PHAstimulated production of IL-1 1 , IL-6, or IL-13. The average IL-8 production was greater than the upper limit of normal for our assay $(>10,240 \mathrm{pg} / \mathrm{ml})$ in both neonates and adults. Lastly, we examined tumor growth factor (TGF)- $\beta$ production in cord blood and found that it is significantly lower in neonates $(n=$ 4) (mean: $142 \mathrm{pg} / \mathrm{ml})$ than adults $(n=4)$ (mean: $718 \mathrm{pg} / \mathrm{ml} ; P$ $=0.0385)$ in response to stimulation with PHA.

\section{DISCUSSION}

Here, we demonstrated that MMCs from cord blood produced profoundly lower amounts of IL-17 in response to PHA, a potent $\mathrm{T}$ cell mitogen, as well as the common neonatal pathogens GBS and E. coli. This is in stark contrast to the IL-17 response that was seen with MMCs from healthy adults, and is likely related to the developmental immaturity of the neonatal adaptive immune response. In particular, this suggests that naive human neonates do not possess sufficient Th17 cell populations that adults have acquired through adaptive immunity.

We have previously reported diminished IFN- $\gamma$, IL-12, and IL-18 production by neonatal cord blood mononuclear cells (12-14); this current report adds to the list of known abnormalities in neonatal host defense. We have also previously demonstrated defects in neonatal neutrophil movement that are correctable with recombinant IFN- $\gamma(12)$.

These observations suggest that impaired IL-17 production in human neonates could lead to defective inflammatory cell migration to sites of microbial invasion, resulting in decreased clearance of pathogens such as GBS, and E. coli. Group B Streptococcus and E. coli are leading causes of infections in newborns, resulting in a high degree of morbidity and mortality $(2,10,17)$. In our current study, we clearly demonstrate diminished IL-17 production in human neonates in response to both GBS and E. coli, the first such report to our knowledge. This likely results from a lack of CCR6 ${ }^{+}$, IL- $17^{+}$T-cells in the newborn cord blood. It would be of interest to determine how long this abnormality persists by comparison to infants and toddlers, which we are actively considering for future studies.

Previously, we showed in the Journal of Clinical Investigation (18) that infants who developed GBS sepsis in the neonatal period lacked opsonic antibody to their infecting strains. Later, in the Journal of Experimental Medicine, we demonstrated that neonatal neutrophil activation is abnormal and that neonatal mononuclear cell production of IFN- $\gamma$ is decreased $(11,12)$. Moreover, we showed that added IFN- $\gamma$ enhanced neonatal neutrophil activation and movement $(11,12)$. We also demonstrated decreased production of IFN- $\gamma$, IL-12, and IL-18 in neonatal cells exposed to GBS $(13,14)$. We have also previously demonstrated that in response to PHA stimulation, MMCs from cord blood demonstrate a striking and significantly diminished Th 1 and Th 2 cytokine production profile, including negligible production of IFN- $\gamma$ (results not published). Here, we demonstrate markedly decreased IL-17 production and lower CCR6 $6^{+}$, IL- $17^{+} \mathrm{T}$ cells in the newborn cord blood and show that added IL-17 markedly increases neonatal IFN- $\gamma$ production in response to the common neonatal pathogen GBS. We propose that toll-like receptor signaling, via GBS, likely results in proinflammatory cytokine production that is synergistic for the production of IFN- $\gamma$ with the addition of IL-17, perhaps through a pathway other than through the T-cell receptor.

Using our negative gating strategy, we have derived a CCR6 ${ }^{+}$, IL-1 $7^{+}$T-cell population that may contain very small numbers of other IL-17 producing lymphocytes. We recognize this limitation and point out that these lymphocytes would only represent $1-2 \%$ of the population of $\mathrm{CD}^{+}$cells gated. Although IL-17 producing $\gamma \delta$-T cells can express CCR6, they represent only a very small subset of $\gamma \delta \mathrm{T}$ cells in human neonates (less than 2 percent) and are not likely to be a significant population in our assay system (19). NK-T cells, which can also produce IL-17, represent less than $0.1 \%$ of $\mathrm{CD}^{3+} \mathrm{T}$ cells in cord blood (20).

Recent experiment conducted by de Roock et al. (21) have shown that in the absence of appropriate proinflammatory cytokine stimulation, the transcription factor retinoic acidrelated orphan receptor $\gamma \mathrm{T}$ (ROR $\gamma \mathrm{T})$ is tightly inhibited by FOXP3, resulting in a lack of Th17 cell production human neonates. In this paper, and in previously published data (15), we have found that cord blood MMCs produce a robust IL-6 response to PHA and Toll-like receptor 1-6 stimulation. Both IL-6 and TGF- $\beta$ are required for induction of ROR $\gamma$ T (7). Preliminary data from our laboratory show that TGF- $\beta$ production is significantly lower in neonates compared to adults in response to stimulation with PHA. Perhaps a lack of sustained STAT-3 activation, which is required for FOXP3 to dissociate from ROR $\gamma$ T, is partially due to defective TGF- $\beta$ production. This would help explain the lack of dissociation of FOXP3 from ROR $\gamma$ T observed by de Rook et al.

In conclusion, we have demonstrated profoundly diminished IL-17 production by human neonatal mononuclear cells and a significantly decreased population of CCR $6^{+} \mathrm{IL}-17^{+} \mathrm{T}$ cells in umbilical cord blood. IL-17 has an important effect on the immune response to bacterial and fungal infections; thus, a deficiency of IL-17 likely has a profound effect on immune and inflammatory function in the newborn infant. This current study is one of the first to describe defective intracellular formation of IL-17, and decreased IL-17 responses to GBS and E. coli by neonatal MMCs as well as a marked decrease in CCR6 $6^{+}$, IL- $17^{+}$Th17 cells in newborn cord blood, which likely contributes to the human neonates increased susceptibility to microbial infections.

\section{METHODS}

\section{Leukocyte Preparation}

Umbilical cord blood was collected after healthy, full-term deliveries and whole blood was collected from healthy adults in sterile tubes containing acid citrate dextrose solution A (Becton Dickinson, Franklin Lakes, NJ). MMCs were isolated from umbilical cord blood or adult whole blood by density gradient centrifugation on Ficoll-Paque Plus separation media (endotoxin tested $<0.12 \mathrm{EU} /$ ml; Amersham Pharmacia Biotech, Piscataway, NJ). The cell layer containing MMCs was removed, washed, and adjusted to a final 
concentration of $1.0 \times 10^{6} / \mathrm{ml}$ in sterile filtered RPMI 1640 tissue culture medium.

\section{Cytokine Production}

Phytohemagglutinin (PHA-P; Sigma-Aldrich, St Louis, MO) was employed as a T-cell mitogen for the stimulation of IL-17 production. $\mathrm{COH}-1$, an encapsulated type III group B Streptococcus strain, and E. coli ON-2 were incubated overnight in Todd Hewitt broth (Difco, Detroit, MI) at $37^{\circ} \mathrm{C}$. Bacteria were washed with phosphate-buffered saline, heat-killed, and adjusted to an OD of 0.9 at $620 \mathrm{~nm}$ wavelength $\left(\sim 5.0 \times 10^{8}\right.$ colony-forming units $\left./ \mathrm{ml}\right)$. Media alone was used as a negative control.

$100 \mu \mathrm{l}$ of MMCs were mixed with $100 \mu \mathrm{l}$ of either stimulant or media in tissue culture plates and incubated for $24 \mathrm{~h}$ at $37^{\circ} \mathrm{C}$ with $5 \%$ added $\mathrm{CO}_{2}$. Tissue culture plates were centrifuged and the supernatant harvested for multianalyte cytokine analysis. In selected experiments, recombinant human IL-17 in a concentration of $100 \mathrm{ng} / \mathrm{ml}$ was added to neonatal mononuclear cell preparations with and without heat inactivated GBS.

\section{Luminex Multianalyte Profiling}

A multiplexed panel for the detection of 15 cytokines was developed, building upon our previous in-house developed cytokine panel (15), in the ARUP Institute for Experimental and Clinical Pathology, University of Utah, Salt Lake City, which was utilized to assay for TNF- $\alpha$, IL-1 $\beta$, IL-6, IL-8, IL-4, IL-5, IL-10, IL-13, soluble CD40 ligand, IL-2, IL-2R, IL-12, IFN- $\gamma$, TGF- $\beta$, and IL-17.

\section{Flow Cytometry}

Whole blood from healthy adults or cord blood was stimulated with PMA and ionomycin $(1 \mathrm{ng} / \mathrm{ml})$ for $6 \mathrm{~h}$. Monensin was added at the beginning of the incubation to prevent cytokine secretion. T cells were then fixed, permeabilized, and stained with phycoerythrinconjugated anti-human IL-17 antibody. Th17 cells were isolated with allophycocyanin-conjugated anti-human CCR6 antibodies. Cells were then acquired by flow cytometry, gated for 10,000 events. A negative gating strategy was used to isolate $\mathrm{CD} 3^{+} \mathrm{CD} 8^{-} \mathrm{T}$ cells, which contain the $\mathrm{CD} 4^{+} \mathrm{CCR}^{+}$subset.

\section{STAT3 Phosphorylation Assay}

Whole blood from normal adult controls and umbilical cords was incubated for $15 \mathrm{~min}$ at $37^{\circ} \mathrm{C}$ with $50 \mathrm{ng} / \mathrm{ml}$ rhIL-6 (Cell Signaling Technology, Beverly, MA) or $50 \mathrm{ng} / \mathrm{ml}$ PMA (Sigma Chemical, Saint Louis, MO) or phosphate-buffered saline buffer alone (SigmaAldrich). Cells were then treated with Lyse/Fix buffer (BD Phosflow, BD Biosciences, San Jose, CA) for $10 \mathrm{~min}$ at $37^{\circ} \mathrm{C}$. Cells were washed once with phosphate-buffered saline and prechilled permeabilization buffer (BD Phosflow Perm Buffer III, BD Biosciences) was added and incubated for $30 \mathrm{~min}$ on ice. Cells were washed three times with $\mathrm{BD}$ Stain Flow buffer (BD Biosciences). Five microliters of either Alexa Fluor 647 Anti-Stat3 pY705 or pS727 were added to $50 \mu \mathrm{l}$ cells, incubated for $60 \mathrm{~min}$ at room temperature, washed and resuspended in BD Stain Flow buffer. An equal volume of $2 \%$ paraformaldehyde (Fisher Scientific, Lake Barrington, IL) diluted in Flow buffer was added to achieve a final concentration of $1 \%$ cell fixative. Cell data were acquired on a BD FACS CANTOS II Flow Cytometer.

\section{Statistical Analysis}

Statistical analysis was performed by the biostatistics department of the ARUP Institute for Clinical and Experimental Pathology, the research arm of ARUP Laboratories. Data were analyzed by the unpaired Student $t$-test and the Wilcoxon rank sum test.

\section{Institutional Review Board and Ethics Study Approval}

Institutional Review Board approval and appropriate informed consent was obtained for these studies: University of Utah IRB \# 00013566, and St. Mark's Hospital IRB \# 0213.

\section{Healthy Volunteer Blood Donors}

Healthy volunteers between the ages of 21 and $65 \mathrm{y}$ of age, whose samples were used as controls, were recruited by word-of-mouth (medical students or laboratory personnel working near the vicinity of the research laboratory). After educating the volunteers about the purpose of the study and reviewing the protocol with them, they were given a consent form to read and asked to confer with others (family members, physicians, P.I.) for concerns they may have with participating in this study. There were no time limits and participants were recruited at their volition. Consenting volunteers were asked to sign the study's consent form that had been approved by the University of Utah's Institutional Review Board (IRB \# 00013566).

\section{To-Be-Discarded, Deidentified Cord Blood}

The Institutional Review Boards at the University of Utah (IRB \#00013566) and St. Mark's Hospital (IRB \#0213) approved the exemption of written and verbal consent for the use of the to-be-discarded deidentified cord blood that was obtained from St. Mark's Hospital and utilized in these studies. Cord blood was collected after infant delivery. The umbilical cord is clamped and cut from the infant at delivery. The collected cord blood is part of the discarded after birth.

\section{ACKNOWLEDGMENTS}

We thank Jeannette Hansen Rejali for her exceptional administrative skills and assistance in preparing and submitting the manuscript.

\section{STATEMENT OF FINANCIAL SUPPORT}

The authors certify that they have no affiliations with or involvement in any organization or entity with any financial interest, or nonfinancial interest, in the subject matter or materials discussed in this manuscript. This research was presented, in part, at the annual meeting of the Western Society for Pediatric Research, Carmel, California, January 2011 and 2012. No outside financial assistance was received to support this study.

\section{REFERENCES}

1. Levy O. Innate immunity of the newborn: basic mechanisms and clinical correlates. Nat Rev Immunol 2007;7:379-90.

2. Maródi L. Neonatal innate immunity to infectious agents. Infect Immun 2006;74:1999-2006.

3. Witowski J, Pawlaczyk K, Breborowicz A, et al. IL-17 stimulates intraperitoneal neutrophil infiltration through the release of GRO alpha chemokine from mesothelial cells. J Immunol 2000;165:5814-21.

4. Gaffen SL. Structure and signalling in the IL-17 receptor family. Nat Rev Immunol 2009;9:556-567.

5. Mosmann TR, Coffman RL. TH1 and TH2 cells: different patterns of lymphokine secretion lead to different functional properties. Annu Rev Immunol 1989;7:145-73.

6. Anunziato F, Romagnani S. Do studies in humans better depict Th17 cells? Blood 2009;114:2213-2219.

7. Korn T, Bettelli E, Oukka M, Kuchroo VK. IL-17 and Th17 Cells. Annu Rev Immunol 2009;27:485-517.

8. Happel KI, Zheng M, Young E, et al. Cutting edge: roles of Toll-like receptor 4 and IL-23 in IL-17 expression in response to Klebsiella pneumoniae infection. J Immunol 2003;170:4432-6.

9. Ishigame H, Kakuta S, Nagai T, et al. Differential roles of interleukin-17A and $-17 \mathrm{~F}$ in host defense against mucoepithelial bacterial infection and allergic responses. Immunity 2009;30:108-19.

10. Huang W, Na L, Fidel PL, Schwarzenberger P. Requirement of interleukin17A for systemic anti-Candida albicans host defense in mice. J Infect Dis 2004; 190:624-31.

11. Sacchi F, Hill HR. Defective membrane potential changes in neutrophils from human neonates. J Exp Med 1984;160:1247-52.

12. Hill HR, Augustine NH, Jaffe HS. Human recombinant interferon gamma enhances neonatal polymorphonuclear leukocyte activation and movement, and increases free intracellular calcium. J Exp Med 1991;173:767-70.

13. Caron JE, La Pine TR, Augustine NH, Martins TB, Hill HR. Multiplex analysis of toll-like receptor-stimulated neonatal cytokine response. Neonatology 2010;97:266-73.

14. La Pine TR, Joyner JL, Augustine NH, Kwak SD, Hill HR. Defective production of IL-18 and IL-12 by cord blood mononuclear cells influences the Thelper-1 interferon gamma response to group B Streptococci. Pediatr Res 2003;54:276-81.

15. Martins TB, Pasi BM, Pickering JW, Jaskowski TD, Litwin CM, Hill HR. Determination of cytokine responses using a multiplexed fluorescent microsphere immunoassay. Am J Clin Pathol 2002;118:346-53. 
16. Eyerich K, Foerster S, Rombold S, et al. Patients with chronic mucocutaneous candidiasis exhibit reduced production of Th17-associated cytokines IL-17 and IL-22. J Invest Dermatol 2008;128:2640-5.

17. Hill HR. Group B streptococcal infections. In: Holmes KK, Mardh PA, Sparling PF, eds. Sexually Transmitted Diseases. New York, New York, USA: McGraw-Hill, 1990:851-61.

18. Hemming VG, Hall RT, Rhodes PG, Shigeoka AO, Hill HR. Assessment of group B streptococcal opsonins in human and rabbit serum by neutrophil chemiluminescence. J Clin Invest 1976;58:1379-87.
19. Morita CT, Parker CM, Brenner MB, Band H. TCR usage and functional capabilities of human gamma delta $\mathrm{T}$ cells at birth. J Immunol 1994;153:3979-88.

20. Sharma AA, Chew L, Ladd M, Jen R, Lavoie PM. Ex vivo purification and characterization of human invariant Natural Killer T cells. J Immunol Methods 2011;373:1-7.

21. de Roock S, Stoppelenburg AJ, Scholman R, et al. Defective TH17 development in human neonatal T cells involves reduced RORC2 mRNA content. J Allergy Clin Immunol 2013;132:754-756.e3. 